\title{
Avian Mycobacteriosis in a Rescued Harpy Eagle from Darien Forest, Panama
}

\author{
Claudia del Carmen Rengifo-Herrera, ${ }^{1,2}$, Julio César Reyes Herrera ${ }^{3,4,5}$, Angie Marie Magaña ${ }^{6}$, \\ Fermín Acosta ${ }^{2}$, Julia Ponder7 \& Amador Goodridge²
}

\begin{abstract}
Background: The Harpy eagle (Harpia harpyia) is the largest raptor in the Neotropical region, distributed in low densities within primary forest habitats from southern Mexico to east-central Brazil, including Central America and Panama. Although locally extinct due to habitat degradation, human poaching and reduction of tropical forests in recent decades, some remnant populations are known to be small and isolated. Thus, information on its ecology, including infectious diseases, is critical for conservation efforts and management of populations of this emblematic species in the wild. Avian Mycobacteriosis (AM) is a chronic disease affecting a wide range of birds and mammals and clinical cases have been sporadically reported, although in harpy eagles, has not been documented. In addition, scant information exists on pathologies affecting raptors, therefore, this report expands the knowledge on infectious diseases affecting wild birds. This study describes the first case of AM in an immature harpy eagle rescued from Darien gap and presents details of the clinical manifestation of the disease and its histological findings.

Case: An immature harpy eagle was presented to a rescue center after being confiscated by Ministry of Environment from a local farm in a remote region of Eastern Panama, in the Darien gap. The raptor had a history of having been kept in captivity for approximately five weeks, cohabiting with backyard poultry and fed corn, raw duck and chicken provided by farm owners. Stagnant water was offered for drinking. The harpy eagle arrived to the facility very lethargic and emaciated. Physical examination revealed damaged plumage, poor body condition and dyspnea. Complete blood count revealed anemia and leukocytosis based on lymphocytosis and eosinophilia. Biochemical profile evidenced an increased level of aspartate aminotransferase (AST), phosphorus and total plasma protein. Most remarkable radiographic findings were splenomegaly, hepatomegaly and increased opacity in kidneys, intestines, and aerial sacs. None of the other diagnostic tests performed were conclusive, like tracheal, esophageal and cloacal cultures for fungal infection and fecal exam. After one week of treatment, it showed a remarkable recovery, but at the end of the second week, declined dramatically, dying in the third week of treatment. Post-mortem examination revealed the presence of diffuse granulomas in multiple organs. Histologic examination with gram and Ziehl Neelsen staining revealed the presence of gram-positive and acid-fast bacteria, compatible with Mycobacterium-like bacilli. PCR-restriction fragment length polymorphism analysis of the hsp65, digested with BstEII and HaEIII restriction enzymes confirmed the presence Mycobacterium avium complex in tissues samples.

Discussion: This is the first report of AM in a harpy eagle, presenting an extreme emaciation with dyspnea, abnormalities in spleen, liver and air sacs. Biochemical and hematological parameters revealed alterations consistent with infection and organ malfunctions in liver, but Mycobacteriosis was not suspected initially and it was necessary to support the diagnosis with histopathological studies and DNA amplification for a proper identification of the disease. This allowed us to confirm that ante-mortem clinical diagnosis of Avian Mycobacteriosis can be challenging, especially in birds who usually show non-specific signs of the disease and external lesions are not commonly observed. Further studies are requiring to determine the characteristics and clinical signs of this disease in this and other raptors. Also, to determine the source of infection affecting raptors and other protected species in the Neotropical region, especially for diseases with relevance in the conservation of birds and animal health control.
\end{abstract}

Keywords: Mycobacteriosis, Mycobacterium avium, Harpia harpyia, Darien gap, Eastern Panama. de Investigaciones Científicas y Servicios de Alta Tecnología, Asociación de Interés Público (INDICASAT-AIP). Ciudad del Saber (Clayton), Panama. ${ }^{3}$ Parque Municipal Summit, Panama City. ${ }^{4}$ Asociación Panamericana para la Conservación (APPC), Gamboa, Panama City. ${ }^{5}$ Centro Veterinario Panama, Panama City. ${ }^{6}$ Centro de Diagnóstico e Investigación Veterinaria (CEDIIVET), Panama City. ${ }^{7}$ Raptor Center, College of Veterinary Medicine, University of Minnesota, MN, USA. CORRESPONDENCE: J.C. Reyes [panamavetdoc@gmail.com]. Centro Veterinario Panamá. 2250 NW 114th Ave Unit 1P. ZC 33192-4177 Miami, FL. 


\section{INTRODUCTION}

The Harpy eagle (Harpia harpyia) is the only extant member of the genus Harpia, an endangered and threatened species according to the Convention on International Trade of Endangered Species of Wild Fauna and Flora (CITES) and the International Union of Conservation of Nature (IUCN) [1,4,5]. The harpy eagle is the largest raptor in the Neotropical region, distributed in low densities within primary forest habitats from southern Mexico to east-central Brazil, including Central America and the isthmus of Panama [1,11]. Although locally extinct in some regions, mostly due to habitat degradation, human poaching and reduction of tropical forests in recent decades [4], some remnant populations are known to be small and isolated. Thus, information on its ecology, including infectious diseases, is critical for conservation efforts and management of populations of this emblematic species in the wild.

Mycobacteriosis in harpy eagles has not been documented, yet, there are a few published reports in other raptors [6,7,9,19,25]. Avian Mycobacteriosis (AM) is a chronic disease affecting a wide range of birds and mammals and clinical cases have been sporadically reported in wild birds [9,11,25]. In addition, scant information exists on pathologies affecting raptors, therefore, this report expands the knowledge on infectious diseases affecting wild raptors. This study describes the first case of AM in an immature harpy eagle rescued from Darien gap and presents details of the clinical manifestation of the disease and its histological findings.

\section{CASE}

An approximately 9-month-old, immature male harpy eagle (Harpia harpyia) was presented to Asociación Panamericana para la Conservación (APPC), a rescue center located in Gamboa, Panama City, after being confiscated by Ministry of Environment from a local farm in a remote region of the Darien gap, in Eastern Panama. The harpy eagle had a history of having been kept in captivity for approximately five weeks, cohabiting with backyard poultry and fed corn, raw duck and chicken provided by farm owners. Stagnant water was offered for drinking. The raptor arrived to the rescue facility very lethargic and emaciated. For a complete physical examination and diagnostic tests, the eagle was physically restrained using towels, according to the technique described by Harrison [1].
Physical examination revealed damaged plumage, poor body condition (weight $2.7 \mathrm{~kg}$, body condition score 1 out of 5 [16], and marked dyspnea with rattling noises on lungs auscultation. At the rescue center, the animal presented regurgitation, green urates, clinical signs of dehydration, and a marked polydipsia. Due to the respiratory involvement, a differential diagnosis of bacterial or fungal disease, such as chlamydiosis or aspergillosis, was considered most likely. Metabolic disease, which could not be ruled out without further diagnostic testing, was also considered due to the imbalanced nutrition offered during captivity in the farm.

Additional diagnostic tests were performed, including a complete blood count (CBC) and plasma biochemical profile (total proteins, calcium, phosphorus, aspartate aminotransferase (AST), creatine kinase (CK) and uric acid); survey radiographs; tracheal, esophageal and cloacal cultures (fungal) and fecal exam. Hematological parameters considered normal for harpy eagles were inferred from other raptors [14].

Blood smear and fecal results were within normal limits. Cultures were negative for fungal growth. Abnormal findings in $\mathrm{CBC}$ were anemia (Hemoglobin $5.3 \mathrm{~g} / \mathrm{dL})$ and mild leukocytosis (26,800 103/ $\mu \mathrm{L})$ based on lymphocytosis $(68 \%)$ and eosinophilia $(23 \%)$. Biochemical profile results were compared to reference values of other raptor species (Table 1), and presumed to demonstrate an increased level of AST (979 U/L), serum phosphorus $(20.0 \mathrm{mg} / \mathrm{dL})$ and total serum protein $(7.9 \mathrm{~g} / \mathrm{dL})$. Serum levels of CK (1511 $\mathrm{U} / \mathrm{L})$, calcium (11.8 mg/dL) and uric acid (12.7 mg/ dL) were within normal range for other raptors.

Abnormalities observed on radiology were splenomegaly, hepatomegaly, decreased cardiac silhouette size, increased soft tissue opacity in kidneys and intestines, and irregular air sac opacities, specifically in the cranial thoracic air sac (Figures $1 \& 2$ ).

The bird was provided supportive care beginning the day after arrival, which included physiologic fluids, $120 \mathrm{~mL}$ SC (Lactated Ringer's solution) ${ }^{1}$, gavage feeding of $300 \mathrm{~g}$ macerated rabbit carcass, 50 $\mathrm{mg} / \mathrm{kg}$ PO Metronidazole ${ }^{2}$ (Flagyl $250 \mathrm{mg} / 5 \mathrm{~mL}^{\circledR}$ ), $22 \mathrm{mg} / \mathrm{kg}$ PO Terbinafine ${ }^{3}$ (Micofin $^{\circledR} 5 \%$ ), $7 \mathrm{mg} / \mathrm{kg}$ PO Itraconazole ${ }^{4}$ (traconazol ${ }^{\circledR} 100 \mathrm{mg}$ ), and $0.5 \mathrm{mg} /$ $\mathrm{kg}$ PO Meloxicam ${ }^{5}$ (Meloxic $\left.{ }^{\circledR} 0.5 \%\right)$. After one week of treatment, the harpy eagle showed a remarkable recovery, consisting in increased appetite and activity. 
At the end of the second week, however, the raptor's health status declined dramatically and it died in the third week of treatment.

Post-mortem examination revealed the presence of multifocal granulomas in the heart, lungs, air sacs, spleen, liver, gallbladder and abdominal wall (Figures 3 \& 4). Histologic examination with haematoxylin and eosin (H\&E) staining revealed gliosis with multifocal satellitosis, neuronophagia and chromatolysis, and diffuse congestion and edema in encephalon. A severe and diffuse atrophy with perivascular fibrosis and granulomatous phlebitis was observed in the pancreas. In the kidneys, severe multifocal granulomatous glomerulonephritis with glomerular sclerosis were also observed. The ventriculus, proventriculus and intestines showed moderate to severe edema with extensive granulomatous inflammation. Heart, lungs, air sacs serous membranes, spleen, liver, gallbladder and abdominal muscles revealed a severe multifocal granulomatous inflammation. As no identifiable gonadal or adrenal glandular tissue was found, it had probably been fully replaced by the granulomatous process. Microscopic examination with gram and Ziehl Neelsen staining of the affected tissues revealed the presence of intralesional gram-positive, acid-fast bacteria, compatible with Mycobacterium-like bacilli. This Mycobacterium-like organism was also observed in the intraluminal space of intestines, suggesting active release to the environment.

To characterize the Mycobacterium-like organisms, samples of granulomas from liver, spleen, lymph node, hilum and intestine were submitted for molecular identification. Enzymatic DNA extraction using lysozymes was performed according to the protocol described by Rosas et al. [18]. Molecular identification was based on PCR-restriction fragment length polymorphism analysis (PRA) of the hsp65 as previously described [22,23]. The hsp65 gen was digested with BstEII and HaEIII restriction enzymes and restriction patterns were analyzed using a UV Transiluminator6. Sizes of patterns were compared to PRAsite database (http://app.chuv.ch/prasite/index. html), characterizing the presence of Mycobacterium avium Complex (MAC) in liver and spleen.

\section{DISCUSSION}

Avian Mycobacteriosis (AM) is a chronic, infectious disease caused mainly by MAC, although other non-tuberculous mycobacteria may also cause this disease in captive, exotic, wild and domestic birds and mammals [25]. In raptors, there are only a small number of published reports worldwide $[6,7,9,19]$. Both free living and captive raptors have been shown to be susceptible to this microorganism, although clinical cases have only been sporadically reported in free-living animals, suggesting a low prevalence of the disease in wild populations [9,13]. Harpy eagles are one of the largest raptors in the Neotropical region, feeding on arboreal prey and nesting in emergent canopy trees [1]. They require large expanses of forest for survival, however, as a result of increasingly reduced and fragmented tropical forests, their population is decreasing [8]. In addition, in regions where deforestation is intense, genetic diversity in populations has been also decreasing [1].

Pathogenic mycobacterial species, which persist in the environment for long periods of time, are capable of evading the host immune system and become a threat to many bird species, especially endangered ones that live in harsh environments such as harpy eagles. This harsh environment reduced immunity and predisposes to infectious diseases [7].

Ante-mortem clinical diagnosis of AM can be challenging as birds usually show non-specific signs of the disease [3]. In general, external lesions are not commonly observed; the most common features described have been emaciation with evident atrophy of pectoral muscles and prominent keel, accompanied by a chronic, progressive wasting and weakness. Other clinical signs described in birds include diarrhea and respiratory alterations $[3,25]$. In this clinical report, the harpy eagle presented an extreme emaciation with dyspnea. Radiographic studies showed abnormalities, most markedly in spleen, liver and air sacs, while biochemical and hematological parameters revealed alterations consistent with infection and organ malfunctions, especially in liver (AST and total proteins). Cultures did not reveal the presence of other pathogens, and mycobacteriosis was not suspected initially because respiratory disorders due to opportunistic bacteria or fungal etiology have been considered the primary cause of illness [20]. It was necessary to support the diagnosis with histopathological studies and DNA amplification for a proper identification of the etiological agent, and therefore the disease. Likewise, the extensive involvement of the respiratory system, especially lungs and air sacs, suggest potential airborne 


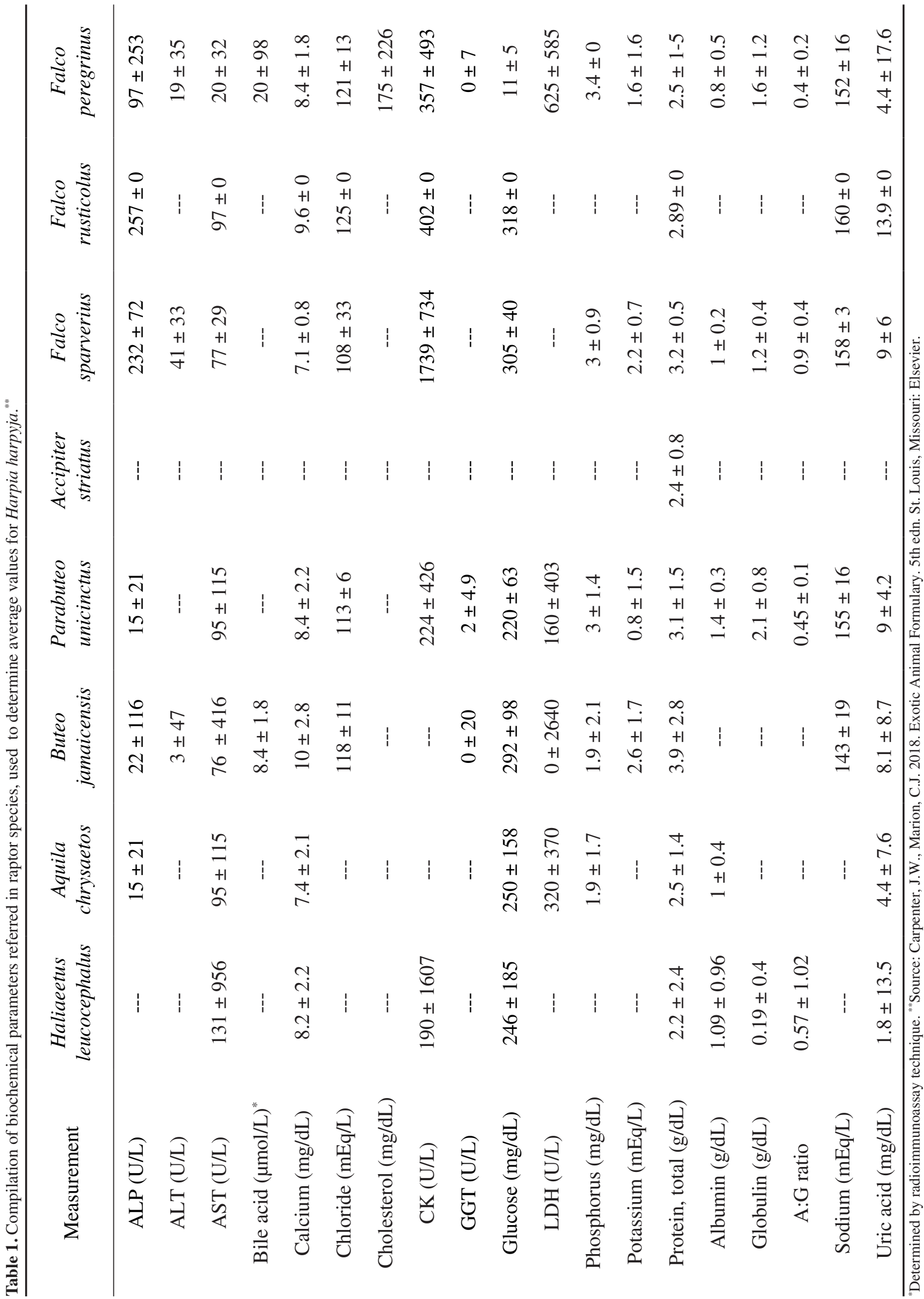




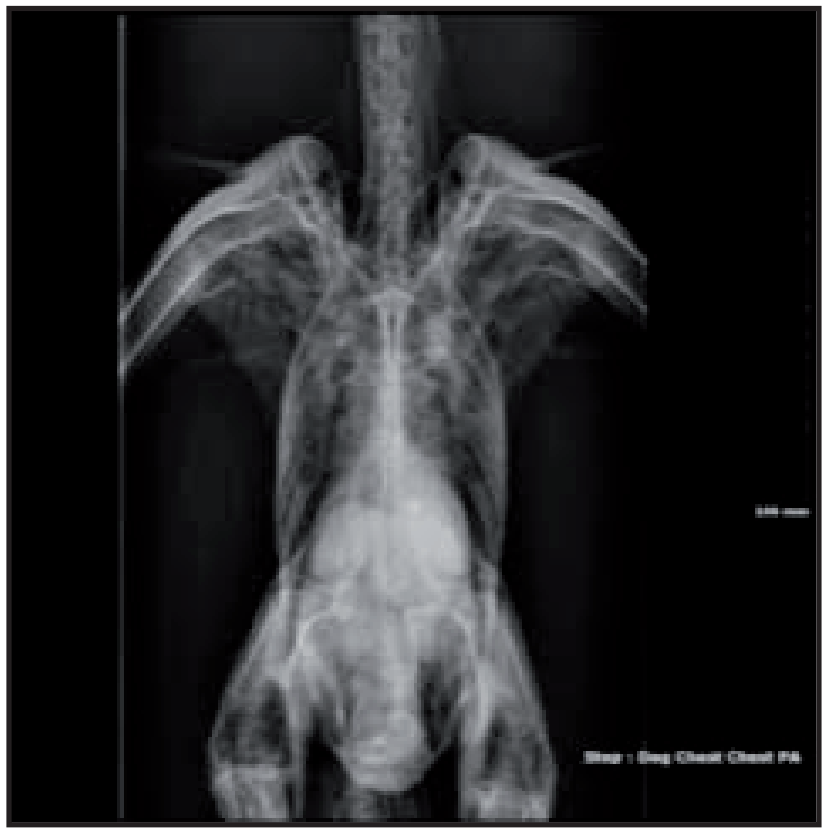

Figure 1. Coelomic radiology of Harpy eagle, anterior posterior view with multiple opacities in air sacs.

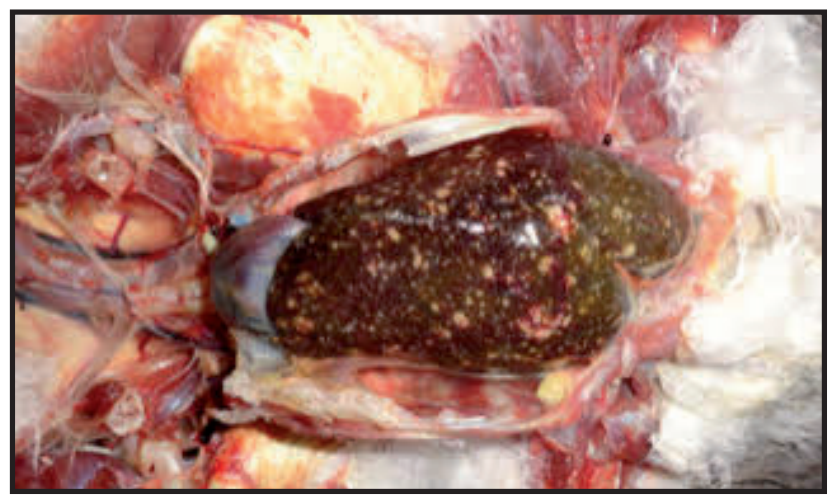

Figure 3. Enlarged liver with rounded edges, friable and abundant yellow granulomas.

transmission, even though oral route cannot be ruled out considering the alterations in the intestine walls and the presence of Mycobacterium-like bacilli in intraluminal space. The oral route has been described as the primary mode of transmission for infected animals in contact with contaminated water and soil $[21,25]$. However, further studies are requiring to elucidate the characteristics and clinical signs of this disease in harpy eagles and other raptors.

Gross pathology lesions can be variable for AM, depending on the affected species, stage of the disease, age, concurrent infections, host's immune and nutritional status, and genetics of mycobacterial species involved in the infection [21]. In this particular case, the patient may have been predisposed to immunosuppression and disease by the presence of stressors such as inadequate environment and nutritional conditions

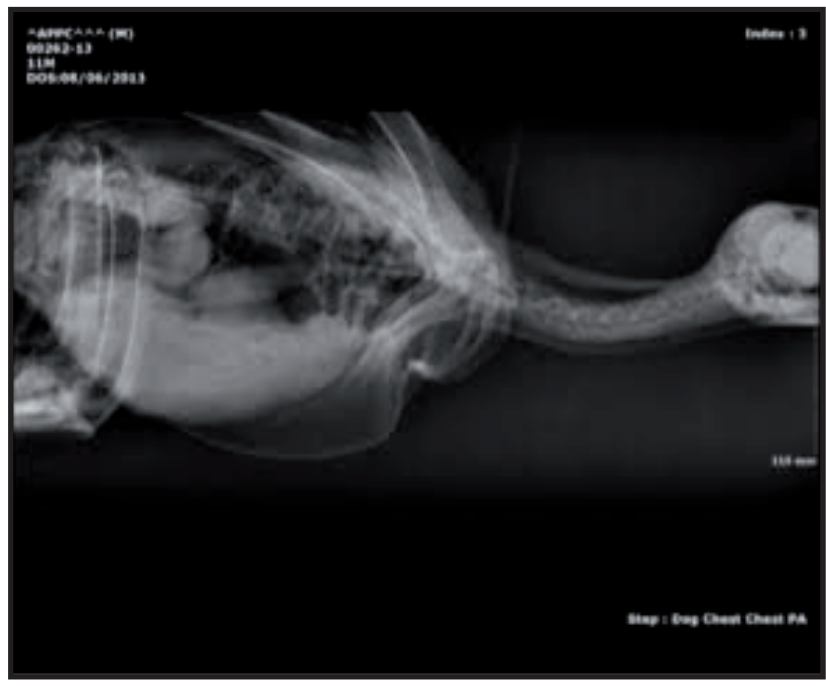

Figure 2. Radiography of cranial coelom in harpy eagle, left lateral view with multiple nodular opacities in lung fields.

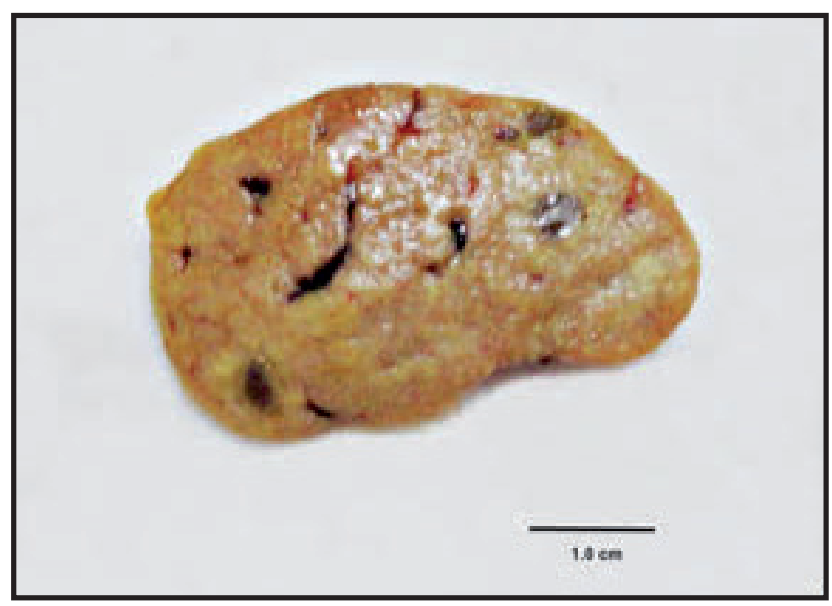

Figure 4. Diffuse yellow granulomas in markedly vascularized spleen measuring approximately $3.0 \mathrm{~cm}$ in length. At the cut, $90 \%$ of the tissue was replaced by granulomas adjoining with each other.

subjected during captivity or transportation, resulting in disseminated disease and widespread granulomatous nodules severely affecting organ tissues.

One of the most evident clinical signs observed during the physical examination was the marked polydipsia. While it may have been caused by dehydration, the absence of identifiable gonadal and adrenal glandular tissues evidenced during histological examination might suggest hormone imbalance as the primary cause, as described by Matos [12]. The role of the adrenal glands in the maintenance of homeostasis, the control of immune regulation and the response to stress is well known. Hormonal dysfunction contributes to an increased susceptibility to infections and the inability to control electrolyte balance, although it is likely that adrenal hormone insufficiency may progress to death before an appropriate diagnostic test can be performed [12]. 
Several mycobacterial species have been involved in the etiology of AM, most of them members of the MAC: M. avium, M. intracelulare and M. avium silvaticum are considered the primary causes of disease in raptors $[6,13,19,25]$. M. avium is divided into three subspecies according to the current taxonomical classification: M. avium paratuberculosis, M. avium avium and $M$. avium silvaticum. In addition, the designation of M. avium hominissuis has been also proposed for human/porcine-type M. avium isolate. These four subspecies differ greatly in their host range, growth potential and environmental occurrence [17]. M. avium paratuberculosis have been described in sheep and is considered the etiological agent of Johne's disease in humans; M. avium silvaticum have been described in wood pigeons, crane, penguin, roader and hazel hen; and $M$. avium avium have been isolated in domestic poultry and is considered the main pathogen of AM in birds and mammals [10,17,24].

In this clinical report, histopathology demonstrated the presence of acid-fast microorganisms, suggesting the presence of Mycobacterium-like bacilli. To identify the etiological agent more specifically, we applied a molecular typing method of microbial pathogens based on PRA analysis, which has been used successfully to characterize Mycobacterium ssp. [15]. This molecular epidemiology allowed the identification of the etiological agent as MAC.

In wild raptors, most reported cases of Mycobacteriosis were caused by $M$. avium serotype 2 [6]. The serotype identified in the harpy eagle, however, was type 1 . This suggests domestic birds as the primary source of infection, considering type 1 the most prevalent in gallinaceous poultry and wild birds raised in captivity [25]. A clinical evaluation of animals in the farm where the harpy eagle was found and a molecular survey could help to find the source of the infection and the epidemiology of the disease.

In conclusion, to the best of knowledge, this is the first case report of AM in a harpy eagle. The loss of habitat and the increasing interaction between wild raptors and human-altered landscapes, including agricultural activities, address to consider AM a risk factor in the conservation of harpy eagles. For this, further studies are requiring to determine the source of infection affecting raptors and other protected species in Neotropical region.

\section{MANUFACTURERS}

\footnotetext{
${ }^{1}$ Laboratorios PiSA, SA de CV. Jalisco, Mexico.

${ }^{2}$ Sanofi-Aventis Canada Inc. Laval, Canada.

${ }^{3}$ Riverfarma, SA de CV. Coyoacán, Mexico D.F.

${ }^{4}$ Calox. San José, Costa Rica.

${ }^{5}$ Laboratorios Provet S.A.S. Bogotá, Colombia.

${ }^{6}$ Ultra Lum Inc. Claremont, CA, USA.
}

Acknowledgments. We would like to thank Nestor Correa MSc, and APPC staff for their invaluable support during handling and care of the animal in the facilities. FA was funded by grant from MEF-IFARHU of Panama. CRH and AG thank the National Secretary of Science, Technology and Innovation through the National Research System (SNI-SENACYT), Republic of Panama. This work was also possible with the financial support of Nestor Correa and Julio Cesar Reyes.

Declaration of interest. The authors declare that they have no conflict of interest. The authors alone are responsible for the content and writing of this case report.

\section{REFERENCES}

1 Banhos A., Hrbek T., Sanaiotti T.M. \& Farias I.P. 2016. Reduction of genetic diversity of the Harpy Eagle in Brazilian tropical forests. PLoS One 11(1): 1-12.

2 Convention on International Trade in Endangered Species of Wild Fauna and Flora.(CITES). Checklist of CITES Species. Available in <https://www.cites.org/eng/app/appendices.php>. [Accessed online April 2019].

3 Dahlhausen B., Tovar D.S. \& Saggese M.D. 2012. Diagnosis of mycobacterial infections in the exotic pet patient with emphasis on birds. Veterinary Clinics: Exotic Animal Practice. 15(1): 71-83 .

4 Food and Agriculture Organization of the United Nations (FAO). 2014. State of the World's Forests. Enhancing the socioeconomic benefits from forests. Rome: FAO, 118p.

5 Harrison G.J. \& Ligthfoot T. 2005. Clinical Avian Medicine. v. 1 \& 2. Palm Beach: Editorial Spix Publishing, 1008p.

6 Heatley J.J., Mitchell M.M., Roy A., Cho D.Y., Williams D.L. \& Tully T.N. 2007. Disseminated mycobacteriosis in a bald eagle (Haliaeetus leucocephalus). Journal of Avian Medicine and Surgery. 21(3): 201-209.

7 Hoenerhoff M., Kiupel M., Sikarskie J., Bolin C., Simmons H. \& Fitzgerald S. 2004. Mycobacteriosis in an American bald eagle (Haliaeetus leucocephalus). Avian Diseases. 48(2): 437-441.

8 International Union for Conservation of Nature (IUCN). IUCN Red List of Threatened Species Available in $<$ https:// www.iucnredlist.org>. [Accessed online April 2019]. 
9 Kriz P., Kaevska M., Bartejsova I. \& Pavlik I. 2013. Mycobacterium avium subsp. avium Found in Raptors Exposed to Infected Domestic Fowl. Avian Diseases. 57(3): 688-692.

10 Leão S.C., Briones M.R.S., Sircili M.P., Balian S.C., Mores N. \& Ferreira-Neto J.S. 1999. Identification of two novel Mycobacterium avium allelic variants in pig and human isolates from Brazil by PCR-restriction enzyme analysis. Journal of Clinical Microbiology. 37(8):2592-2597.

11 Lerner H.R.L., Johnson J.A., Lindsay A.R., Kiff L.F. \& Mindell D.P. 2009. It's not too late for the harpy eagle (Harpia harpyja): High levels of genetic diversity and differentiation can fuel conservation programs. PLoS One.4(10): $1-10$.

12 Matos R. 2008. Adrenal Steroid Metabolism in Birds: Anatomy, Physiology, and Clinical Considerations. Veterinary Clinics of North America: Exotic Animal Practice. 11(1): 35-57.

13 Millán J., Negre N., Castellanos E., de Juan L., Mateos A., Parpal L. \& Aranaz A. 2010. Avian mycobacteriosis in free-living raptors in Majorca Island, Spain. Avian Pathology. 39(1): 1-6.

14 Oliveira M.J., Nascimento I.A., Ribeiro V.O, Cortes L.A., Fernandes R.D., Santos L.C., Moraes W. \& Cubas Z.S. 2014. Haematological values for captive harpy eagle (Harpia harpyja). Pesquisa Veterinária Brasileira. 34(8): 805-809.

15 Parvandar-Asadollahi K., Mosavari N. \& Mayahi M. 2015. Genotyping of Mycobacterium avium subsp. avium isolates from naturally infected lofts of domestic pigeons in ahvaz by IS901 RFLP. Iranian Journal of Microbiology. 7(5): 260-264.

16 Pollock C. 2012. Body condition scoring in birds. LafeberVet Website. Available in $<$ https://lafeber.com/vet/es/indicede-condicion-corporal-en-las aves/\#Evaluando_la_condicion_corporal_en_las_aves_adultas $>$. [Accessed online in March 2019].

17 Rónai Z., Csivincsik Á. \& Dán Á. 2015. Molecular identification of Mycobacterium avium subsp. silvaticum by duplex high-resolution melt analysis and subspecies-specific real-time PCR. Journal of Clinical Microbiology. 53(5): 1582-1587.

18 Rosas S., Bravo J., Gonzalez F., Moreno N., Sanchez J., Gavilan R.G. \& Goodridge A. 2013. High clustering rates of multidrug-resistant Mycobacterium tuberculosis genotypes in Panama. BMC Infectious Diseases. 13: 442.

19 Sadar M.J., McRuer D., Hawkins M.G. \& Armién A.G. 2015. Multifocal Respiratory and Vertebral Mycobacteriosis in a Red-tailed Hawk (Buteo jamaicensis). Journal of Zoo and Wildlife Medicine. 46(1): 150-154.

20 Shankar B.P. 2008. Common Respiratory Diseases of Poultry. Veterinary World. 1(7): 217-219.

21 Shivaprasad H.L. \& Palmieri C. 2012. Pathology of Mycobacteriosis in Birds. Veterinary Clinics of North America: Exotic Animal Practice. 15: 41-55.

22 Silva C.F., Ueki S.Y.M., Geiger D.D.C.P. \& Leão S.C. 2001. hsp65 PCR-restriction enzyme analysis (PRA) for identification of mycobacteria in the clinical laboratory. Revista do Instituto de Medicina Tropical de São Paulo. 43(1): 25-28.

23 Telenti A., Marchesi F., Balz M., Bally F., Bottger E. \& Thomas B. 1993. Rapid identification of mycobacteria to the species level by polymerase chain reaction and restriction enzyme analysis. Journal of Clinical Microbiology. 31(2): 175-178.

24 Turenne C.Y., Semret M., Cousins D.V., Collins D.M. \& Behr M.A. 2006. Sequencing of hsp65 Distinguishes among Subsets of the Mycobacterium avium Complex. Journal of Clinical Microbiology. 44(2): 433-440.

25 World Animal Health (OIE). 2014. Avian Tuberculosis. OIE Terrestrial Manual. Paris: OIE, 111p. 